\title{
Research on Zoning for Rural Residential land in Shanyang County Based on Rural Vitalization
}

\author{
Minjie Kong \\ College of Urban and Environmental Sciences \\ Northwest University \\ Xi'an710127, China \\ 15691853498@163.com \\ Jing Han \\ College of Urban and Environmental Sciences \\ Northwest University \\ Xi'an710127, China
}

\author{
Zhao Wang \\ College of Urban and Environmental Sciences \\ Northwest University \\ Xi'an710127, China \\ Tongsheng $\mathrm{Li}^{*}$ \\ College of Urban and Environmental Sciences \\ Northwest University \\ Xi'an710127, China \\ Email: leetang@nwu.edu.cn
}

\begin{abstract}
By researching on Shanyang County, Shaanxi Province which owns plenty of villages, this paper builds a evaluation index system of the rural residential land potential consolidation. With the aid of the BP neural network model of particle swarm optimization and the hierarchical clustering analysis method, the index of the rural residential land potential consolidation of Shanyang County was synthetically measured to divide rural residential land consolidation and further explore the corresponding arrangement strategies. The conclusions are drawn as follows: the high-value areas of the rural residential land potential consolidation of Shanyang County are centered in the areas with flat terrain, convenient transportation, close distance to the central city, and excellent social and economic development. Based on the results of hierarchical clustering analysis and the current situation of rural development, Shanyang County is divided into urban development area, priority consolidation area, key consolidation area, moderate consolidation area, and control adjustment area. Targeted consolidation strategies and optimization approaches are proposed in accordance with the principle of regional planning and local conditions, providing references for rural vitalization.
\end{abstract}

Keywords—rural vitalization; rural residential land; PSO-BP neural network; hierarchical clustering analysis; zoning of land consolidation

\section{INTRODUCTION}

The lag of rural development has undermined the building of a well-off society in an all-round way. In 2017, the 19th National Congress of the Communist Party of China (PCP) proposed the strategy of rural vitalization to alleviate issues of the uncoordinated urban-rural development ${ }^{[1]}$. As an integral part of the rural regional system, residential land, with spatial arrangement and adjustment makes great influences for rural revitalization. The literature from foreign scholars are mostly based on the land consolidation ${ }^{[2]}$, hierarchical organization ${ }^{[3]}$, landscape patterns of rural settlements ${ }^{[4]}$, etc. While in China, the scholars focused on the spatial arrangement optimization, the consolidation potential evaluation of residential land,

Sponsor: Under the auspices of National Nature Sciences Foundation of China (Research on Behavior and Mechanism of New Agricultural Management Entities' Technology Adoption under Innovation Diffusion of Agricultural Science and Technology Park. No.41771129) consolidating the subareas and strategies, and other aspects. $\mathrm{Li}$ Shanshan with other researchers applied kernel density estimation, space hot spot detection, and other methods to study the spatial distribution characteristics of rural residential land ${ }^{[5]}$; some scholars probed the spatial distribution and optimization of rural residential land with Voronoi diagram ${ }^{[6-7]}$ Most of them measured and calculated the consolidation potential of residential land from the provincial and county territory ${ }^{[8]}$. The scholars consolidate zones of residential land from different perspectives and put forward development strategy, regarding the consolidation zone and strategies. In the construction of indicator system of consolidation potential, indicator weight mostly applies the subjective methods to valuate, lacking preciseness and fairness; in the course of consolidating the zones, most of the provincial and county territory are done, with the short of the village as the unit being zoned. In view of this, we build consolidation potential evaluation index system of country residential areas, taking Qinba Mountainous Area, Shanyang County, Shaanxi Province for instance, and administrative village as the studying unit. This research uses BP model of Particle Swarm Optimization(PSO) to quantitatively analyse the consolidation potential of residential areas, and delimit and zone the land. This paper aims to provide the decision basis for the consolidation of residential areas of poverty-stricken mountainous areas and realizing rural revitalization.

\section{RESEARCH AREA AND DATA}

\section{A. Research area}

Shanyang County is located in the south of Shangluo City, Shaanxi Province (Fig.1), County-wide total area $3535 \mathrm{~km}^{2}$, It has 2 sub-district offices, 16 towns and 239 administrative villages. The terrain in the territory changes greatly, and natural disasters occur frequently. According to the second national land survey data of Shanyang County, the rural residential area of the county is $6469.57 \mathrm{hm}^{2}$, accounting for $1.83 \%$ of the total area. 


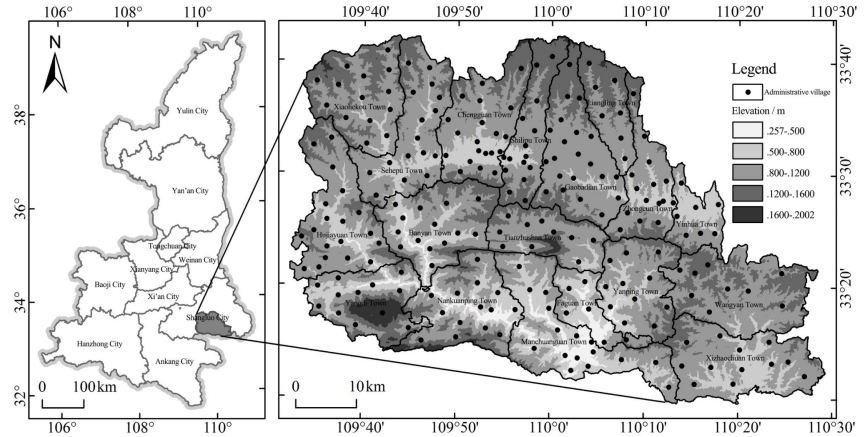

Fig. 1. The location of the study case

\section{B. Data}

The 238 villages of Shanyang County, Shaanxi Province are regarded as the research unit. Since data on the Dongguan village in Chengguan town is missing, this research does not included this village. The digital elevation model (DEM) data of $30 \mathrm{~m}$ resolution ratio is from geospatial data cloud website (http://www.gscloud.cn). The river data is from the Bureau of Land Resources of Shanyang County. Annual precipitation data is from resource and environmental data cloud platform of Chinese Academy of Sciences (http://www.resdc.cn). The possibility data of geographical hazards are from the thirteenth Five-Year Plan of geological disaster prevention and control. The land use data is from Bureau of Land Resources of Shanyang County, socioeconomic data is from $<2015$ Statistical Yearbook of Shanyang County> and poverty relief in the thirteenth Five-Year Plan. ArcGIS10.2 is used to get the minimum range from the water and road network of density, center of mass of each administrative village, to center of county, road and river system, and to extract the gradient, altitude data, and calculate the topographic relief.

\section{METHODOLOGIES}

\section{A. Index system}

Combining the current situation of Shanyang County in Qinba Mountains Area, which is supported by the available literature $^{[9]}, 20$ items of evaluation factors were selected from dimensions of natural resources, land location, as well as social economic status. The evaluation index system of the rural residential land potential consolidation of Shanyang County was built (table1), evaluation of the present conditions and development potential of the residential areas in the administrative villages of Shanyang County.

Natural resources condition, to certain extent, reflects the feasibility of consolidation of rural residential areas, decides the indicators of elevation, gradient, topographic relief, annual precipitation, the density of water network and the possibility of natural hazards, and so on. In the land use, patch area and patch density of residential areas can reflect its scale and cluster degree of residential areas. The more the agricultural acreage per capita, the smaller the motivation that the farmers will consolidate. The external condition refers to the minimum range from county, traffic artery and waters reflect whether the peasant's production is convenient. The density of roads reflects the degree of cooperation and connection among patches of residential areas. The social-economic level reflects the economic feasibility of the consolidation potential of rural residential areas ${ }^{[10]}$. Thus the indicators of population density, disposable income per capita of farmers, changing rate of transfer of rural labor, and others are chosen to reflect the social economic-development level of villages.

\section{B. PSO-BP neural network}

Based on existing research results, this paper believes that the rural residential area is a complex regional area generated under the interaction of multiple elements, including natural resources, land location, and social-economic status. It can present an uncertain nonlinear complicated relation under the interaction of various elements. The reference relates to the research $^{[11]}$, that we apply PSO to optimize the BP neural network(Fig.2). PSO algorithm can optimize the initial weight value and the threshold value of each layer in the BP neural network, look for the globally optimal solution fast and effectively, and offset the weakness of BP neural network.

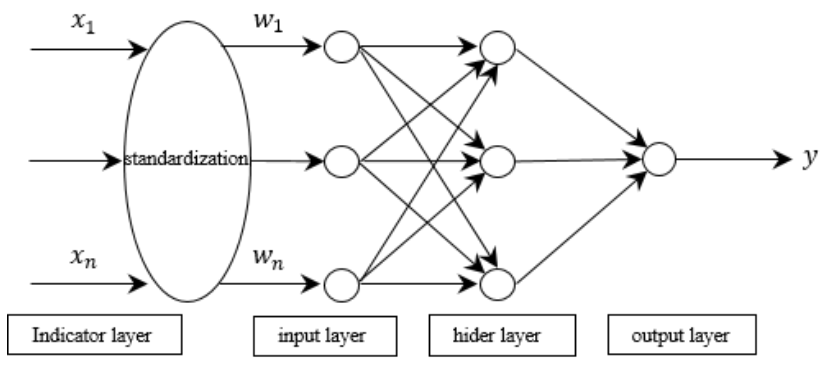

Fig. 2. Topology diagram of BP neural network

After the range standardization of index data of Shanyang County, it can be taken as the nature of the input layer of PSOBP neural network model. The input layer can correspond to natural resource index(NRI), land location index(LLI), and social-economic index(SEI), to build the PSO-BP neural network model of rural residential consolidation potential index(RRCPI) . Its calculation formula is:

\section{$\mathrm{RRCPI}=\mathrm{NRI}+\mathrm{LLI}+\mathrm{SEI}$}

The larger the potential index, the higher the consolidation potential of rural residential, conversely, the smaller the consolidation potential. 
TABLE I.

POTENTIAL EVALUATION INDEX SYSTEM FOR COMPREHENSIVE CONSOLIDATION OF RURAL RESIDENTIAL LAND

\begin{tabular}{|c|c|c|c|}
\hline Target layer & Rule layer & Indicator layer & Calculation method \\
\hline \multirow{20}{*}{$\begin{array}{l}\text { Potential evaluation of rural } \\
\text { residential land }\end{array}$} & \multirow{6}{*}{$\begin{array}{l}\text { Natural resource } \\
\text { conditions }\end{array}$} & Elevation $(\mathrm{m})$ & $30 \mathrm{~m} \times 30 \mathrm{~m}$ Shanyang county's DEM \\
\hline & & Slope $\left(^{\circ}\right)$ & Slope analysis of arcgis \\
\hline & & Degree of relief $(\mathrm{m})$ & Grid statistics of arcgis \\
\hline & & $\begin{array}{l}\text { Density of water network } \\
\left(\mathrm{km} / \mathrm{km}^{2}\right)\end{array}$ & Density analysis of arcgis \\
\hline & & Average annual rainfall $(\mathrm{ml})$ & Interpolation calculation of arcgis \\
\hline & & $\begin{array}{c}\text { Susceptibility of the geological } \\
\text { disaster }\end{array}$ & Classification assignment \\
\hline & \multirow{8}{*}{$\begin{array}{l}\text { Land location } \\
\text { conditions }\end{array}$} & $\begin{array}{c}\text { Per capita cultivated land area }(\mathrm{Mu} \\
\text { per person) }\end{array}$ & Cultivated land area / total population of administrative villages \\
\hline & & $\begin{array}{c}\text { Per capita residential area (pers/ } \\
\mathrm{km}^{2} \text { ) }\end{array}$ & Total population / administrative village residential area \\
\hline & & $\begin{array}{l}\text { Residential plaque density (One } \\
\text { per square kilometer) }\end{array}$ & $\begin{array}{c}\text { Number of plaques in residential areas / total area of } \\
\text { administrative villages }\end{array}$ \\
\hline & & Density of road network $\left(\mathrm{km} / \mathrm{km}^{2}\right)$ & Density analysis of arcgis \\
\hline & & $\begin{array}{l}\text { Distance from the county center } \\
(\mathrm{km})\end{array}$ & Neighborhood analysis of arcgis \\
\hline & & $\begin{array}{l}\text { Distance from the nearest town } \\
\text { center }(\mathrm{km})\end{array}$ & Neighborhood analysis of arcgis \\
\hline & & $\begin{array}{l}\text { Distance from the nearest road } \\
(\mathrm{km})\end{array}$ & Neighborhood analysis of arcgis \\
\hline & & $\begin{array}{l}\text { Distance from the nearest drainage } \\
\text { system }(\mathrm{km})\end{array}$ & Neighborhood analysis of arcgis \\
\hline & \multirow{6}{*}{$\begin{array}{l}\text { Society and economy } \\
\text { conditions }\end{array}$} & Density of population (pers $/ \mathrm{km}^{2}$ ) & Number of people / total area of administrative village \\
\hline & & Rural per capita net income (yuan) & Statistical data \\
\hline & & $\begin{array}{l}\text { Rural labor transfer rate of change } \\
(\%)\end{array}$ & $\begin{array}{c}\text { Number of migrant workers / total number of administrative } \\
\text { villages }\end{array}$ \\
\hline & & $\begin{array}{c}\text { Proportion of farmers' professional } \\
\text { cooperatives }(\%)\end{array}$ & $\begin{array}{l}\text { Number of households registered by farmers' professional } \\
\text { cooperatives / total number of administrative villages }\end{array}$ \\
\hline & & Rate of dilapidated housing (\%) & $\begin{array}{c}\text { Number of dangerous houses / total number of administrative } \\
\text { villages }\end{array}$ \\
\hline & & Rate of rural poverty (\%) & Number of poor / total number of administrative villages \\
\hline
\end{tabular}

\section{Hierarchical clustering analysis}

Hierarchical clustering is an important sorting method to study quantitively the geographic zone. It clusters objects sharing most similarity according to the affinity of cases or variables $^{[12]}$, which. With the help of SPSS 20.0, choose Euclidean distance to calculate the similarities among villages in Shanyang County, apply group average method to cluster. The specific formulas refer to the literature ${ }^{[13]}$.

\section{RESULTS AND ANALYSIS}

\section{A. Rural residential consolidation potential index}

The formula (1) aims to calculate the consolidation potential index of the rural residential. ArcGIS10.2 software was used to visualize the distribution of rural residential consolidation potential index and its single dimension index (Fig.3).
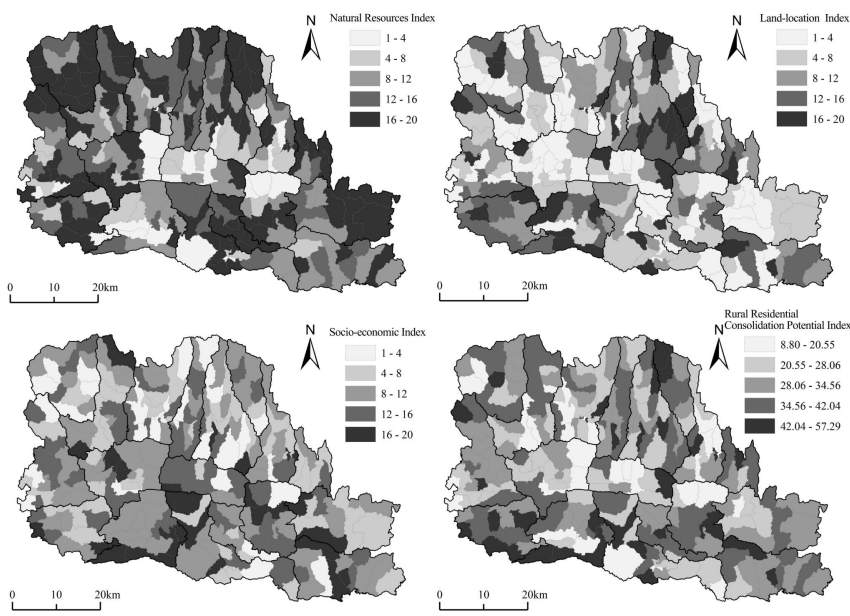

Fig. 3. Spatial distribution of rural residential consolidation potential index and its single dimension index in Shanyang

High-value area of natural resources index focuses on the regions that are flat, gentle terrain, and the geological disasters rarely happen. The high-value area of land location index focuses on the regions with big site area of residential area per capita, dense road network, convenient traffic and significant proximity to the county center. The high-value area of socialeconomic index concentrates on the regions that are well developed as of social and economic aspects. The maximum, minimum, and average value of consolidation potential index 
of rural residential areas of Shanyang County is respectively: $57.29,8.80,31.95$. Through the Nature breaks grading method in ArcGIS, the rural residential consolidation potential is divided into five levels, which are between 8.80 20.55,20.56 28.06,28.07 3.56,34.57 42.04, $42.05 \sim 57.29$.

\section{B. Zoning of rural residential land consolidation and strategy}

Hierarchical clustering analysis of natural resource index, soil location index and social-economic index, Combined with the cultural characteristics and related planning of Shanyang County, divides Shanyang County into urban development area, priority consolidation area, key consolidation area, moderate consolidation area, and control adjustment area (Fig.4).

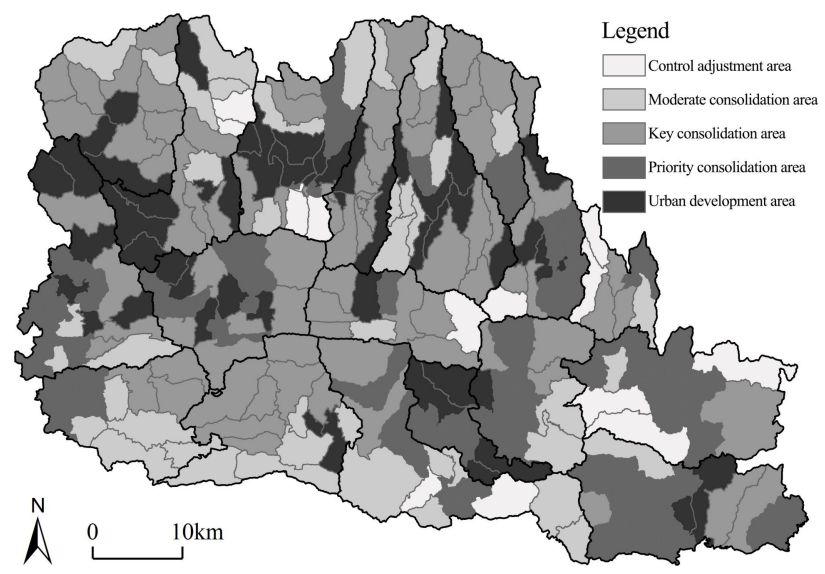

Fig. 4. Zoning of rural residential land consolidation in Sanyang

(1) Urban development area. The residential area is $1575.85 \mathrm{hm}^{2}$, accounting for $24.57 \%$ of the total residential area. These regions mainly locate around the central towns and close to the highly-developed cities and towns, much driven by cities and towns. Shanyang County is a comprehensive pilot of national targeted poverty reduction and new-type urbanization. The residential areas of this region can rely on it, accelerate the progress of urbanization, strengthen the driving capacity of major cities and towns, enhance regional development vitality and improve the infrastructures and public service construction in the region.

(2) Priority consolidation area. The residential area is $1257.48 \mathrm{hm}^{2}$, accounting for $19.56 \%$ of the total residential area. These regions are located in the West and Southeast part of Shanyang County, with superior geographical conditions, good economic foundation, the residents mostly live around the road and river systems. That the city system planning of Shanyang County are development conditions of each town and selected standard of national characteristic town, this region can majorly build the characteristic town based on convenient location, livable geographic environment, sophisticated facilities and services, and other advantages. Retain the old village setup with a historical appeal, dig the local characteristic, enhance the organic integration of modern agriculture, experience agriculture, homestay and tourism, and other rural diversity commercial businesses.
(3) Key consolidation area. The residential area is 2241.89 $\mathrm{hm}^{2}$, accounting for $34.87 \%$ of the total residential area. It is the largest district among five residential areas. It is closer to the center of town, and can be driven by the central town, to a certain degree, and has a concrete economic foundation. We should plan reasonably on the current residential areas while consolidating; enhance regional ecological and cultural function. Strictly control the newly constructed house site, control the development scale of villages. Increase the cultivated area, and promote the scale operation of agriculture.

(4) Moderate consolidation area. The residential area is $899.13 \mathrm{hm}^{2}$, accounting for $13.99 \%$ of the total residential area This region is mostly at the edge of towns, where has backward economic development, poor living condition, and insufficient resource allocation and infrastructures. Therefore, the consolidation of residential areas of this region applies the model of digging the potential interiorly, takes different measures for each town and cities, consolidate them from easy to difficult. Reclaim the unused and deserted residential areas to ensure the development of agriculture. Vitalize the abandoned house sites; arrange the people in one place.

(5) Control adjustment area. The residential area is 450.51 $\mathrm{hm}^{2}$, accounting for $7.01 \%$ of the total residential area. Shanyang County is of landform mainly consisting of the mountainous region, which accounts for $82 \%$ of total area. This region is centered on the mountain land with high altitude with the zoology being fragile and geographical disasters being frequently taking place. It is far from central town, and economic development is slower than others. Affected by terrain factor, the residential areas are scattered around this region, with many unused deserted residential areas. The consolidation of residential areas of this region should pay attention to the size control, gradually moving the residents to the regions of a better natural environment. The land after consolidation need to be reclaimed and returned to forestry, which can improve the positive cycle of the ecosystem.

\section{CONCLUSION}

(1) Rural revitalization is a major strategic decision raised to cope with the increasingly serious rural "aging or weakening". Accessing the consolidation potential of rural residential land can promote the effective and intensive use of land resources, integrate mutually the rural land industries, population and other elements, and people's well-being aiming at realizing the comprehensive rejuvenation in rural areas by systematically allocating and efficiently managing various developmental elements.

(2) Most of the high-value areas in Shanyang County are centered in the areas with flat terrain, large per capita residential area, convenient transportation, being close to the central city, and with good social and economic development. The PSO-BP neural network model can more accurately determine the index weights, making the measurement results more objective.

(3) Shanyang County is divided into urban development area, priority consolidation area, key consolidation area, moderate consolidation area and control adjustment area. Propose the corresponding consolidation strategy. 


\section{REFERENCES}

[1] Liu Y S. Research on the urban-rural integration and rural revitalization in the new era in China[J]. Acta Geographica Sinica, 2018, 73(4):637650. (In Chinese)

[2] Pašakarnis $G$, Maliene $V$. Towards sustainable rural development in Central and Eastern Europe: Applying land consolidation. J. Land Use Policy, pp. 545-549, (27):2010.

[3] Hill M. Rural settlement and the Urban Impact on the Countryside. M. Tianjin: Hodder \& Stoughton, 2003.

[4] Sevenant M, Antrop M. Settlement models, land use and visibility in rural landscapes: Two case studies in Greece. J. Landscape and Urban Planning, pp. 362-374, 4(80):2007.

[5] Li Sh Sh, Cao G C, Zhao P F. Analysis of spatial distribution of rural settlements and its influential factors in Qinba Mountain area: A case study of Ningqiang county in Shaanxi Province[J]. Research of Soil and Water Conservation, 2014, 21(3):186-191. (In Chinese)

[6] Liu Sh K, Wei S Q, Chen S L et al. Voronoi diagram based research on spatial distribution characteristics of rural settlements and consolidation potential evaluation[J]. Resources Science, 2014, 36(11):2282-2290. (In Chinese)

[7] Fan T X, Yang Q Y, He J et al. Spatial distribution optimization of rural residential land in hilly areas: A case study of Haitang town in
Changshou district[J]. Geographical Research, 2015, 34(5):883-894. (In Chinese)

[8] Ta N, Zhang Y F, Zhao M et al. Reclamation potentiality analysis on rural residential land in Inner Mongolia[J]. Economic Geography, 2012, 32(8):136-141. (In Chinese)

[9] Liu J, Jin X B, Fan Y T et al. Rural residential land consolidation strategy from a perspective synthesizing towns, villages and land parcels: A case study in Xinyi city, Jiangsu province[J]. Geographical Research, 2018, 37(4):678-694. (In Chinese)

[10] Chen L, Xin G X, Yuan X Y. On the potential of rural residential land consolidation and its spatial differentiation in the poor mountainous areas [J]. Journal of Southwest University: Natural Science Edition, 2012, 34(1):99-105. (In Chinese)

[11] Pan R Q, Ma XS, Liu J. Calculation model of cultivated land nature quantity score based on PSO-BP Neural Network[J]. Geography and Geo-Information Science, 2014, 30(5):78-82.

[12] Liu Q. Research on land use zoning in Hunan Province[D]. Hunan: Hunan Normal University, 2013. (In Chinese)

[13] Wang J, Wei Ch F, Liu WP et al. Land consolidation zoning in Hilly Areas of Southwest China based on the function of production living and ecology: A case study of Qijiang district of Chongqing city[J]. Areal Research and Development, 2018, 37(3):155-159. (In Chinese) 